Research article

\title{
Spatiotemporal persistence of bat roadkill hotspots in response to dynamics of habitat suitability and activity patterns
}

\author{
Denis Medinas a,b, ", João Tiago Marques ${ }^{\mathrm{a}, \mathrm{c}}$, Pedro Costa ${ }^{\mathrm{a}}$, Sara Santos ${ }^{\mathrm{a}, \mathrm{c}}$, Hugo Rebelo ${ }^{\mathrm{d}, \mathrm{e}, \mathrm{f}}$, A. \\ Márcia Barbosa $^{g}$, António Mira ${ }^{a, c}$ \\ ${ }^{a}$ Conservation Biology Lab, Department of Biology, University of Évora, Pólo da Mitra, 7002-554, Évora, Portugal \\ ${ }^{\mathrm{b}}$ CIBIO/InBIO-UE, Research Centre in Biodiversity and Genetic Resources, University of Évora, Rua Dr. Joaquim Henrique da Fonseca, 2nd, 7002-554, Évora, Portugal \\ ${ }^{c}$ MED Institute, Universidade de Évora, Pólo da Mitra, 7006-554, Évora, Portugal \\ d CIBIO/InBIO-UP, Research Centre in Biodiversity and Genetic Resources, University of Porto, Rua Padre Armando Quintas, 4485-661, Vairão, Portugal \\ e CEABN-InBIO, Centre for Applied Ecology "Prof. Baeta Neves", Institute of Agronomy, University of Lisbon, Tapada da Ajuda, 1349-017, Lisbon, Portugal \\ ${ }^{\mathrm{f}}$ School of Biological Sciences, University of Bristol, Woodland Road, Bristol BS8 1UG, Bristol, UK \\ ${ }^{g}$ CICGE (Centre for Research in Geo-Spatial Sciences), University of Porto, Observatório Astronómico Prof. Manuel de Barros, Alameda Do Monte da Virgem, 4430-146, \\ Vila Nova de Gaia, Portugal
}

\section{A R T I C L E I N F O}

\section{Keywords:}

Hotspot location changes

Remote sensing

Vegetation productivity

Water stress

Spatial clustering

Road management

\begin{abstract}
A B S T R A C T
Wildlife roadkill hotspots are frequently used to identify priority locations for implementing mitigation measures. However, understanding the landscape-context and the spatial and temporal dynamics of these hotspots is challenging. Here, we investigate the factors that drive the spatiotemporal variation of bat mortality hotspots on roads along three years. We hypothesize that hotspot locations occur where bat activity is higher and that this activity is related to vegetation density and productivity, probably because this is associated with food availability. Statistically significant clusters of bat-vehicle collisions for each year were identified using the Kernel Density Estimation (KDE) approach. Additionally, we used a spatiotemporal analysis and generalized linear mixed models to evaluate the effect of local spatiotemporal variation of environmental indices and bat activity to predict the variation on roadkill hotspot locations and to asses hotspot strength over time. Between 2009 and 2011 we conducted daily surveys of bat casualties along a 51-km-long transect that incorporates different types of roads in southern Portugal. We found 509 casualties and we identified 86 statistically significant roadkill hotspots, which comprised $12 \%$ of the road network length and contained $61 \%$ of the casualties. Hotspots tended to be located in areas with higher accumulation of vegetation productivity along the three-year period, high bat activity and low temperature. Furthermore, we found that only $17 \%$ of the road network length was consistently classified as hotspots across all years; while $43 \%$ of hotspots vanished in consecutive years and $40 \%$ of new road segments were classified as hotspots. Thus, non-persistent hotspots were the most frequent category. Spatiotemporal changes in hotspot location are associated with decreasing vegetation production and increasing water stress on road surroundings. This supports our hypothesis that a decline on overall vegetation productivity and increase of roadside water deficit, and the presumed lower abundance of prey, have a significant effect on the decrease of bat roadkills. To our knowledge, this is the first study demonstrating that freely available remote sensing data can be a powerful tool to quantify bat roadkill risk and assess its spatiotemporal dynamics.
\end{abstract}

\section{Introduction}

The development of transport infrastructure is one of the main human-related pressures on wildlife (Spellerbeg, 1998; Fahrig and Rytwinski, 2009; Benítez-López et al., 2010), mainly due to habitat fragmentation and degradation (Trombulak and Frissell, 2000; van der Ree et al., 2015). However, the most acknowledged direct impact of roads is wildlife-vehicle collision (WVC), which often contributes to the decline of species of conservation concern (Kociolek et al., 2011; Visintin et al., 2016; Loss et al., 2015). WVCs involving bats are

\footnotetext{
* Corresponding author. Conservation Biology Unit, Department of Biology, University of Évora, Pólo da Mitra, 7002-554, Évora, Portugal.

E-mail addresses: denimedinas@gmail.com, denism@uevora.pt (D. Medinas), jtiagomarques@gmail.com (J.T. Marques), pedrocostabio@hotmail.com (P. Costa), saramsantos@hotmail.com (S. Santos), hugo.rebelo@cibio.up.pt (H. Rebelo), anamarciabarbosa@gmail.com (A.Márcia Barbosa), amira@uevora.pt (A. Mira).
} 
increasingly reported (Choquene, 2006; Lesiński, 2007, 2008; Capo et al., 2006; Gaisler et al., 2009; Medinas et al., 2013; Altringham and Kerth, 2016), and transport infrastructures may be an important factor contributing to the global decline of many bat species (Altringham and Kerth, 2016; Fensome and Mathews, 2016). Indeed, several life-history and ecological traits of bats make them particularly prone to be hit by vehicles. These include migration over considerable distances (Schofield and Mitchell-Jones, 2011), large home ranges (Kelt and Van Vuren, 1999), or feeding opportunities on road verges (Berthinussen and Altringham, 2012; Medinas et al., 2019). Therefore, bat activity may be strongly reduced on road-dominated environments (Berthinussen and Altringham, 2012; Claireau et al., 2019). Moreover, bats are long lived, have low fecundity and late maturation, so they may be unable to withstand even moderate increases in mortality (Schorcht et al., 2009). Thus, roadkills may jeopardize the long-term viability of bat populations.

Several studies reported that patterns of bat casualties are not equally distributed in space. Higher bat mortality rates have been found where bat flyways cross roads with high quality habitats or are close to foraging locations, such as water bodies and riparian galleries (Medinas et al., 2013; Gaisler, 2009; Iković et al., 2014; Lesiński, 2007; Lesiński et al., 2010; Secco et al., 2017). At these locations, bat casualties may be spatially clustered, being designated as roadkill hotspots. These are often computed in a static way for a defined time interval without considering how location changes across time (Malo et al., 2004; Skorka et al., 2015). For instance, bat-vehicle collision patterns are often described annually (Fensome and Mathews, 2016), but substantial inter-annual variations occur and this has been scarcely analyzed. For other mammal species (e.g. mule deer, black bear, lowland tapir) these inter-annual differences are often associated with variations in environmental factors (e.g. land cover or climate), traffic volume or population fluctuations (Seiler and Helldin, 2006; Shilling and Waetjen, 2015; Ascensão et al., 2019). Moreover, some species showed marked seasonality in roadkill occurrences, which were particularly evident in mating and swarming periods (Fensome and Mathews, 2016). Thus, spatial and temporal changes in hotspots can give insights regarding distribution and predictability of important resources on the landscape (Fensome and Mathews, 2016).

The notion of shifting hotspots relates to the concept of home range fidelity (Börger et al., 2006; Freedman and Roy, 2012; Switzer, 1997). The consistent classification of a road section as hotspot over time, termed hotspot fidelity, may reflect the existence of permanent important landscape features for bat ecological needs, such as foraging habitats or roosts in roadsides. In contrast, when resource availability changes in space and time, bat activity will track the resources and hotspots of roadkill may shift accordingly. In these circumstances, spatiotemporal predictability of the hotspots may be low. Unfortunately, there is a dearth of information on factors driving bat roadkills hotspot dynamics, in space and time, likely due to a lack of analytical methods for capturing and characterizing spatiotemporal variability in resource availability at a fine-scale.

The current availability and development of remote sensing techniques allow them to be used for monitoring and mapping of insect outbreaks, particularly to evaluate forest damages caused by defoliators (Zhang et al., 2010). Moreover, there are many studies where remote sensing data of vegetation productivity, land surface temperature and moisture content are indicated as having greater potential for mapping the biomass at higher trophic levels (Jepsen et al., 2009; Rullan-Silva et al., 2013). These studies suggest that spatiotemporal heterogeneity of remote sensing derived indices is intrinsically linked to fluctuations in food resources availability and may provide insight about insect abundance. For instance, the Normal Deviation Vegetation Index (NDVI) has a robust positive linear correlation with ground-based measurements of net primary productivity, such as vegetation cover (Zhang et al., 2010) and, indirectly related to insect abundance in deciduous forest (Spruce et al., 2011). Furthermore, a shortage of water may increase vegetation stress and decrease foliage availability to insects. Blum et al. (2015), showed that the use of land surface temperature resulted in satisfactory estimations of olive fly population trends. Thus, assuming that bats have a higher probability of being roadkilled while foraging in areas with high food resources (Fensome and Mathews, 2016; Medinas et al., 2013), remote sensing data can be a powerful and cost-effective tool for gaining knowledge on spatiotemporal dynamics of bat roadkills.

In this study, we describe bat roadkill patterns along low, medium and high traffic roads in a Mediterranean landscape for three consecutive years. We first assess whether roadkills are spatially clustered forming "hotpots" of mortality. Then we evaluate if roadkill spatiotemporal patterns are similar along the studied years. Finally, we investigate how important are vegetation productivity, moisture content and land surface temperature, acting as a proxy of food availability in explaining roadkill hotspot patterns, taking into account local bat activity and traffic volume. We hypothesize that bat casualties will not be evenly distributed across space, and that there will be aggregations. These will tend to occur in areas with higher vegetation productivity and may vary between years, owing to variation in water availability, temperature or local land management over time. We discuss the applicability of freely available remote sensing data to describe spatial variation in roadkill patterns.

\section{Material and methods}

\subsection{Study area and bat roadkill surveys}

This study was carried out in a landscape of about $400 \mathrm{~km}^{2}$ in southern Portugal $\left(38^{\circ} 32^{\prime} 24^{\prime \prime}\right.$ to $38^{\circ} 47^{\prime} 33^{\prime \prime} \mathrm{N} ; \quad-08^{\circ} 13^{\prime} 33^{\prime \prime}$ to $-07^{\circ} 55^{\prime} 45^{\prime \prime} \mathrm{W}$; Fig. 1). The climate is Mediterranean, with mean daily temperature ranging from 5.8 to $12.8{ }^{\circ} \mathrm{C}$ in January, and from 16.3 to $30.2{ }^{\circ} \mathrm{C}$ in August; annual rainfall averages $609.4 \mathrm{~mm}$ and is concentrated between October and March (Évora, 1971-2000; Instituto de Metereologia, 2010). The topography is flat, with altitude ranging from $100 \mathrm{~m}$ to $400 \mathrm{~m}$ a.s.l. The landscape is dominated by savanna-like forests mainly composed of cork (Quercus suber) and holm-oak (Quercus rotundifolia), alternating with open agricultural areas for cattle grazing and cereal crops, olive groves (Olea europaea), vineyards (Vitis spp.) and woody vegetation along streams.

Bat roadkill surveys were carried out along three national road segments (EN4, EN114 and EN370) and one municipal road segment (M529), comprising a total of $51 \mathrm{~km}$. We surveyed these singlecarriageway roads daily, from the 15th of March to the 15th of October, in 2009, 2010 and 2011. Surveys were conducted by a single observer driving a car at $20-40 \mathrm{~km} / \mathrm{h}$ while scanning the road surface for bat carcasses (details in Santos et al., 2011). These observations started at sunrise, to reduce the impact of scavenger removal, because median persistence time for bat carcasses is one day (Slater, 2002; Santos et al., 2011). Surveys were always carried out by experienced observers (more than five years conducting roadkill surveys), and most ( $>80 \%$ ) were carried out by the same two experienced observers (DM, PC), thereby assuring consistency of procedures and minimising errors due to variation in observer detectability skills. All bat carcasses were collected and later identified to species level using morphological keys (Palmeirim, 1990; Dietz and von Helversen, 2004) or genetic analysis, when the bat had no identifiable external characters (see details Medinas et al., 2013).

\subsection{Bat activity data and traffic surveys}

Bat activity was surveyed in 87 sites across the study area using 15min point counts at the same time period of the roadkill surveys (2009-2011). Each sampling site was visited three times each year, from April until September - the period of the highest bat activity in Mediterranean systems (Rainho, 2007) - with a two-month interval between visits. The sampling sites were at least $1000 \mathrm{~m}$ apart and located on most representative land use categories, and at different distances from roads 

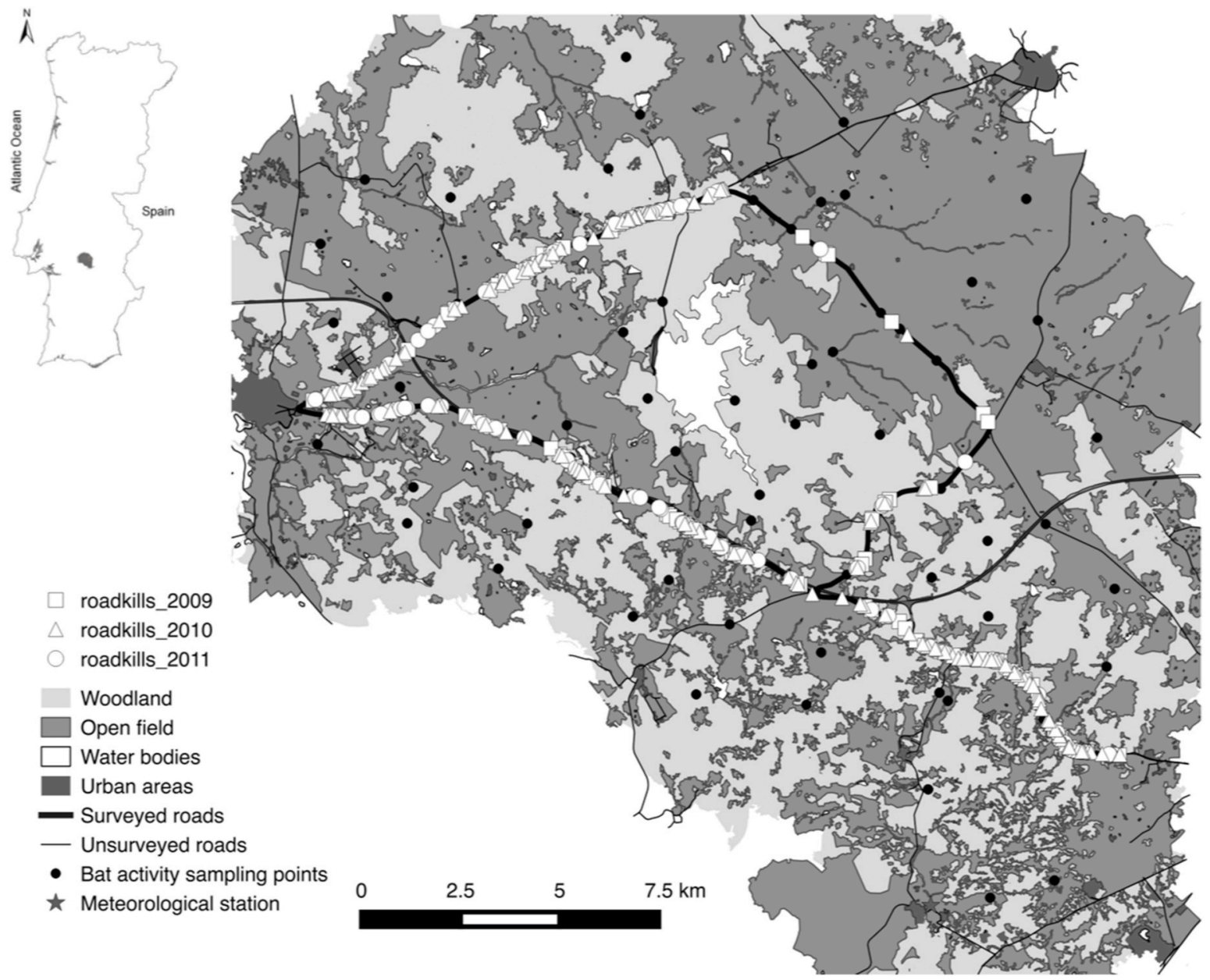

Fig. 1. Map of the study area in southern Portugal, showing the sections of roads that were surveyed (EN114, EN4 and EN370-M529) and the bat acoustic sampling points (black markers). The two main land uses are woodland (light grey) and open field (dark grey) areas. Bat-vehicle collision spots per year were highlighted with white markers.

(Fig. 1). We used a bat detector (D240x bat detector, Pettersson Elektronik AB) and a digital recorder (Archos AV 500 mobile digital video recorder) to record sound samples of each bat pass. The surveys were performed only on dry calm nights, which are the most favourable conditions for bat activity and detectability (Dixon, 2012). We generated yearly bat activity maps for the study area using the inverse distance-weighted interpolation (IDW) of the mean number of bat passes.

Traffic volume estimates were based on, counts of all passing vehicles on 20 bat survey sites located near roads, and they were repeated three times each year. From these data we obtained an estimate of the number of vehicles per hour for every two months between April and September.

Following the classification of the Portuguese Road Institute, surveyed roads according to nocturnal traffic were categorized as: high for EN114 (1210 vehicles/night), medium for N4 (277 vehicles/night), and low for EN370 and M529 (both with $<100$ vehicles night), hereafter analyzed together as EN370-M529 (EP, 2005; see details in Medinas et al., 2013).

\subsection{Definition of hotspots and hotspot strength}

The bat roadkill data were examined for the presence of high mortality clusters, i.e. hotspots, using the Kernel density estimation (KDE) (Okabe et al., 2009; Bíl et al., 2013; Favilli et al., 2018). This approach estimates the probability density function of the underlying data, and was combined with Monte Carlo simulations with a 95\% threshold to evaluate the significance of each hotspot detected. The point pattern density method uses a moving function, controlled by a bandwidth, to weigh the importance of points within the bandwidth. In our analyses, we used a $150 \mathrm{~m}$ bandwidth because it was previously shown that this value is adequate to define roadkill hotspots on low-medium traffic roads (Bíl et al., 2013).

Additionally, we calculated the hotspot strength to rank the hotspots according to their hazardousness or risk. This ranking makes it possible to prioritize the most hazardous hotspots. This relative measure is directly dependent on the number of roadkills recorded in a hotspot and the length of road section, and indirectly related to the length of hotspot and the number of roadkills outside the cluster (Bíl et al., 2019). Hotspot strength estimates how much the observed distribution of mortality values on each hotspot is different from the uniform distribution (Bíl et al., 2013). Monte Carlo simulations and identification of hotspots were performed using the "sparr" package (Davies et al., 2017) and the "spatialEco" package (Evans, 2018) in R software version 3.4.4 (R Development Core Team, 2018). To assess possible spatial correlations between hotspot locations, we calculated the nearest-neighbour distance between centroids of hotspots per each year of survey (D_KDE) and used a Moran'I test to evaluate potential statistical significance. Hotspots distanced up to $50 \mathrm{~m}$ were considered together. 


\subsection{Explanatory variables of bat roadkill hotspots}

To find the best predictors that explain the spatiotemporal persistence of hotspots and their hazardousness (i.e. strength), we used three remote sensing based environmental indices reflecting local dynamics in primary production content (NDVI - Normalized Difference Vegetation Index), water content on surface and vegetation (NDWI - Normalized Differences Water Index), and relative water stress (WETNESS - Wetness Tasseled Cap transformation Index); we also used a remotely sensed daytime land surface temperature (TEMPERATURE). The remotely sensed environmental indices and land surface temperature were obtained from a time series (from January 2007 to December 2011) of Landsat-5 satellite images, gathered from the US Geological Survey (USGS; LP DAAC - http://lpdaac.usgs.gov). The time frame included full calendar years of the study period and three years before its beginning. We only retained high-quality images for the whole study area (WRS-2 scene: path 203 , row 33,30 m resolution) and, among these, we only examined images with less than $20 \%$ cloud cover. All images were preprocessed by applying the radiometric calibration to convert the pixel values to Top-of-Atmosphere reflectance (TOA) (Chander et al., 2009). Each of the remote sensing based environmental indices $(\Phi)$ was created for four time-periods (hereafter scenarios): the year of bat roadkill survey (YEAR_SURVEY; $\Phi_{\mathrm{y}}$ ); the year before the roadkill survey (one YEAR_BEFORE; $\Phi_{1 y}$ ), the whole of the two years before the roadkill survey (two YEARS_BEFORE; $\Phi_{2 y}$ ), and the whole of the three years before the roadkill survey (three YEARS_BEFORE; $\Phi_{3 y}$ ) (Fig. 2). To derive each period composites, we first built a stack of all day-scenes for each scenario. Then, we used a 500-m buffer width around each roadkill hotspot to estimate the mean ( $\left.m_{-} \Phi\right)$, sum (s_ $\left.\Phi\right)$ and standard deviation $\left(s_{-} \Phi\right)$ for each environmental indices. This buffer size was based on the foraging distances regularly covered by most roadkilled bat species in our study area, Pipistrellus kuhlii and P. pygmaeus (Dietz et al., 2009; Medinas et al., 2013). Additionally, we combined remote sensing data with field-measured variables, such as traffic volume and bat activity interpolation (see 2.2 Bat activity data and traffic surveys). Finally, we used a variable selection procedure aiming to reduce the dimensionality and eliminate highly correlated variables (see topic 2.5 ).

\subsection{Statistical analyses for the evaluation of hotspot strength}

We investigated the influence of remotely sensed environmental indices and temperature, traffic volume and bat activity on the strength of hotspots using general linear mixed models (GLMMs) with a Gaussian error distribution and an identity link function. Hotspot location (id) was included as a random factor to account for the probable correlation between successive measurements - different years - at the same location. We also included in our models a first-order autoregressive covariance structure to account for the potential dependence in the

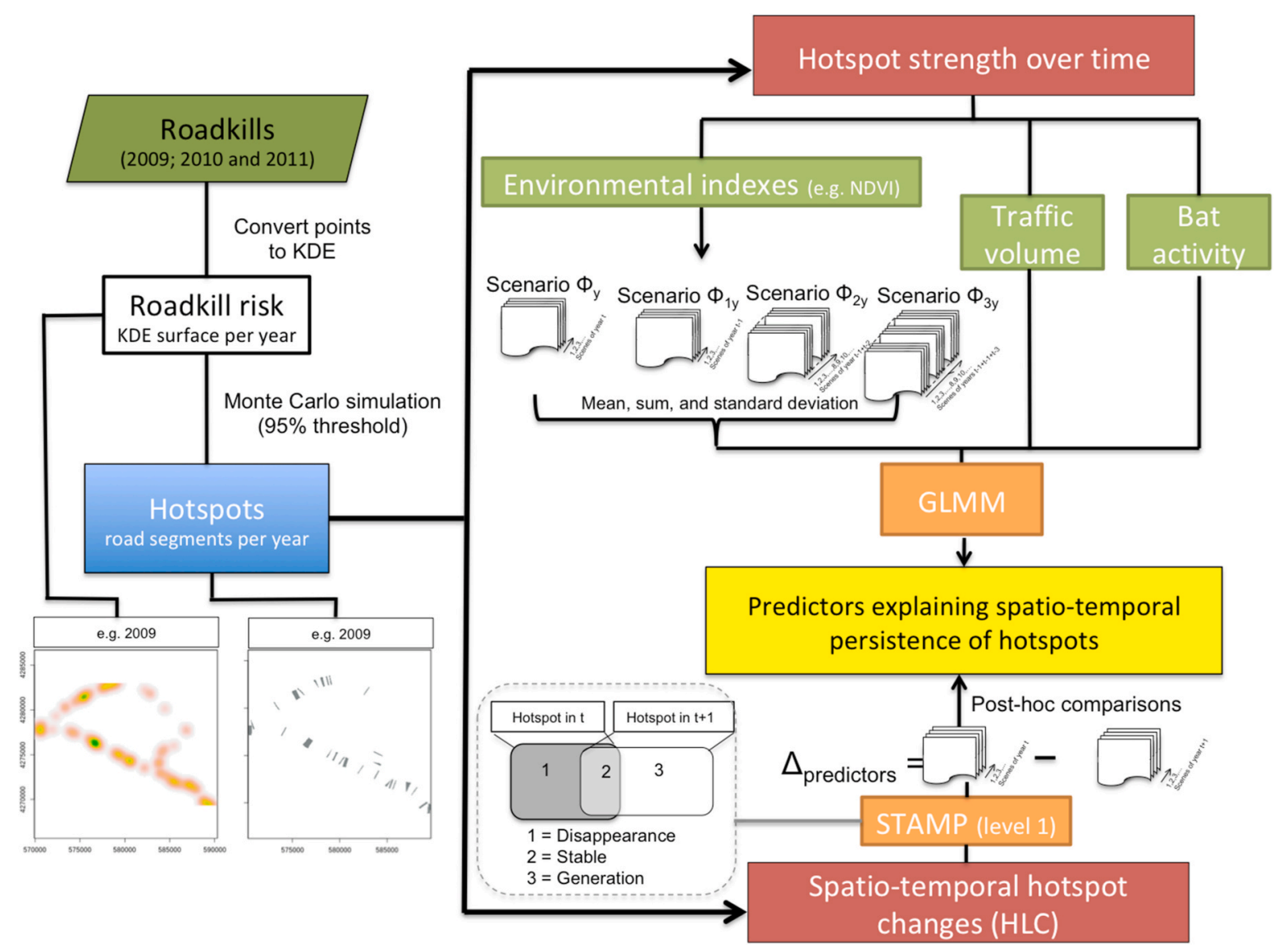

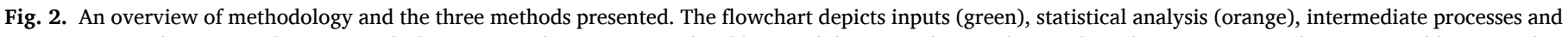

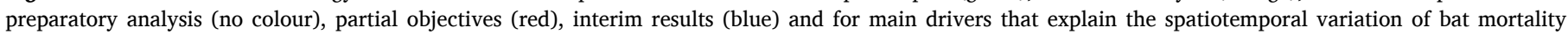

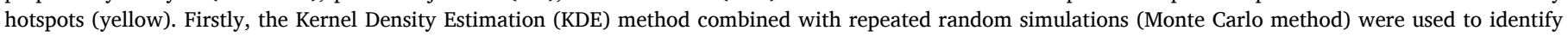

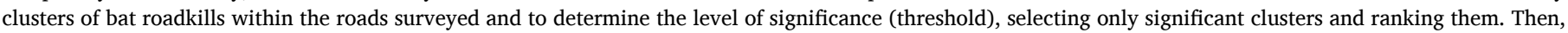

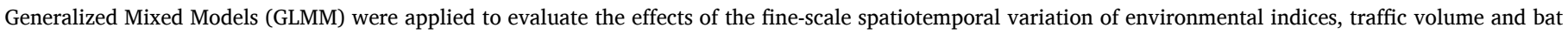

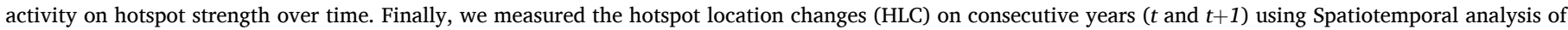

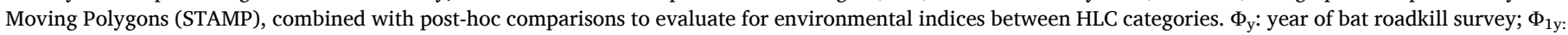

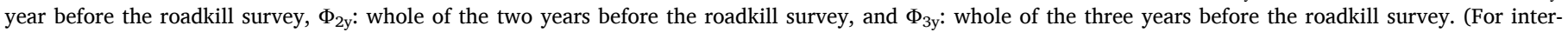
pretation of the references to colour in this figure legend, the reader is referred to the Web version of this article.) 
hotspot locations over sampling years (Zuur et al., 2009).

Prior to modelling, when necessary, we log transformed the explanatory variables to approach normality, homogenise the variance and reduce the influence of outliers (Zuur et al., 2009). All explanatory variables were then standardised to zero mean and unit variance, to allow for comparison of their strength (Burnham and Anderson, 2002). At a first stage, bivariate models were built for each explanatory variable. Only variables statistically significant in the bivariate phase were selected for further multiple variable modelling. To avoid collinearity, prior to modelling, we performed a Spearman correlation analysis among all remaining variables. For pairs of variables with a correlation higher than 0.70 (Dormann et al., 2013), only the variable most related to the hotspot strength was kept for further analysis. After this process, s_NDVIy, s_NDVI $3 y$, s_ACTIVITY, TRAFFIC, s_NDWI, D_KDE $_{-}$and S_TEMPERATURE $\mathrm{y}_{\mathrm{y}}$ were the only predictors retained to build the multiple models (Supplementary Material - Table SM1).

All candidate models were built based on all possible subsets of selected explanatory variables, including the null and full model (Supplementary Material - Table SM2). The full model was structured in the following way:

Strength of Hotspots $\sim s_{-N D V I y}+s_{-N D V I 3 y B}+s_{-A C T I V I T Y}+$ TRAFFIC $+s_{-N D W I y}+$

$D_{-K D E}+s_{-}$TEMPERATUREy, random $=1 \mid$ id, structural correlation $=c$

orAR1 (id / year)

We used the AICc and the corresponding Akaike weights $\left(w_{\mathrm{i}}\right)$ to rank candidate models (Burnham and Anderson, 2002). Because no single model was convincingly the most plausible $\left(w_{\mathrm{i}} \geq 0.95\right.$; Burnham and Anderson, 2002), we performed a model averaging approach, basing the average parameters, unconditional standard errors (SE) and $95 \%$ confidence intervals (CI) inferences on the group of models with $\Delta$ AICc $<2$ (Burnham and Anderson, 2002). Plots of residuals were examined to check for normality, and deviance tests were done to assess the goodness of fit of the final models. All statistical tests were performed using the $\mathrm{R}$ software version 3.4.4 (R Development Core Team, 2018) with the packages "nlme" (Pinheiro et al., 2007) for GLMMs and 'MuMIn' (Barton, 2013) for multi-model inference.

\subsection{Spatiotemporal changes on roadkill hotspots patterns}

To evaluate the spatiotemporal hotspot location changes (HLC), we used a GIS-based method for analysing temporally dynamic polygons (STAMP) (Robertson et al., 2007). This method adds an additional dimension to the analysis by quantifying hotspot shifts between two time periods (Nelson, 2011; Smulders et al., 2012). Thus, within a paired set of hotspot locations on consecutive years ( $t$ and $t+1$ ), each polygon was categorized as one of the HLC categories: (i) stability or fidelity, if the area was identified as hotspot in both $t$ and $t+1$; (ii) generation or expansion, when a new hotspot location was identified in $t+1$ but not classified in $t$; and (iii) disappearance or contraction, when the hotspot location was identified in $t$ but not in $t+1$ (Fig. 2). To compare the changes between HLC categories among years (stable vs. expansion vs. contraction), we calculated the relative proportion of area to each HLC category per year. Additionally, we evaluated differences in explanatory variables $(\Delta \boldsymbol{\Phi})$ in each roadkill polygon between every two consecutive years $(t$ and $t+1)$ and tested these differences among HLC categories. Following tests for normality and homogeneity of variance, we used PERMANOVA procedures and randomized ANOVA comparisons (Sokal and Rohlf, 1995). Whenever significant differences were found, we performed post-hoc comparisons (Tukey's HSD) to test for differences between pair groups (Supplementary Material - Table SM3). STAMP analyses were conducted using R package "stampr" (Long et al., 2018), while the HLC analyses were performed with R package "vegan" (Oksanen et al., 2012).

\section{Results}

\subsection{General bat roadkill patterns}

Between 2009 and 2011, we recorded 509 bat carcasses belonging to 12 species, most of which were Pipistrellus kuhlii (34.5\%), P. pygmaeus (30.8\%), P. pipistrellus (21.9\%), Rhinolophus hipposideros (3.6\%) and Eptesicus serotinus (2.9\%) (Table 1). The total number of bat carcasses per year increased along the three years of the study: 154 in 2009, 176 in 2010 and 179 in 2011 (Fig. 1).

\subsection{Spatiotemporal patterns of roadkill hotspots}

Roadkill hotspot analyses demonstrated different aggregation patterns over the study period (Fig. $3 \mathrm{~A}$ ). In total, we identified 86 bat roadkill hotspots with uneven distribution among years (27 in 2009, 33 in 2010, and 26 in 2011 - Fig. 3 B). The bat mortality in hotspots accounted for more than half of the total bat casualties, 2010 being the year with the highest percentage of mortality in hotspots (2009-57\%; 2010-65\%; and, 2011-60\%). The total length of these hotspots amounts to, on average, $12 \%$ of the road network (2009-9\%; 2010-13\%; 2011-8\%). The average hotspot length also varied among years (2009-175 m; 2010-206 m; 2011-162 m), but these differences were not statistically significant $(\mathrm{F}=0.829, \mathrm{p}=0.44)$.

Concerning temporal changes in hotspots location, 24 hotspots, comprising $3 \%$ of the road length, have remained stable along the three years of the study. On the other hand, hotspot expansion or contraction, between consecutive years had a higher representation on the road network (expansion $-6 \%, n=46$; contraction $-7 \%, n=51$ ).

\subsection{Main drivers of bat roadkill hotspots}

The most hazardous bat roadkill locations - higher hotspot strengths were associated with higher accumulated vegetation productivity along the three-year period previous to the survey $\left(\mathrm{s}_{-} \mathrm{NDVI}_{3 \mathrm{yB}}\right.$ : coef $\left.=0.458\right)$, higher bat activity (s_ACTIVITY: coef $=0.314$ ), and lower daytime land surface temperature (s_TEMPERATURE $\mathrm{y}_{\mathrm{y}}$ : coef $=-0.227$ ). Moreover, both s_NDVI ${ }_{3 y B}$ and s_ACTIVITY had higher importance $(\mathrm{RVI}=1.00$ and 0.5 , respectively) and were included in a higher number of models than S_TEMPERATURE $_{\mathrm{y}}(\mathrm{RVI}=0.3)($ Fig. 4). According to the averaged models, s_TEMPERATURE $E_{y}$ has an equivocal meaning, as zero was included in the unconditional confidence interval (Fig. 4). Contrary to our expectations, traffic volume was not included in any of the final models of hotspot strength. All candidate models with $\Delta$ AICc $<2$ are presented in Table 2.

\subsection{Drivers of spatiotemporal changes in roadkill hotspots}

Regarding temporal hotspot location changes (Fig. 5), the Tukey post hoc test revealed that a positive $\triangle$ NDVI, an increase in primary

Table 1

Yearly distribution of bat carcasses collected.

\begin{tabular}{lllll}
\hline Species & 2009 & 2010 & 2011 & Total \\
\hline Barbastella barbastellus & 3 & - & 1 & 4 \\
Eptesicus isabellinus & - & 1 & - & 1 \\
Eptesicus serotinus & 5 & 3 & 7 & 15 \\
Miniopterus schreibersii & 1 & 2 & - & 3 \\
Myotis daubentonii & 2 & 2 & 4 & 8 \\
Myotis escalerai & 1 & - & - & 1 \\
Nyctalus leisleri & 2 & 4 & - & 6 \\
Pipistrellus kuhlii & 66 & 60 & 53 & 179 \\
Pipistrellus pipistrellus & 21 & 38 & 54 & 113 \\
Pipistrellus pygmaeus & 45 & 58 & 55 & 158 \\
Rhinolophus ferrumequinum & 1 & 2 & - & 3 \\
Rhinolophus hipposideros & 7 & 6 & 5 & 18 \\
Total per year & 154 & 176 & 179 & 509 \\
\hline
\end{tabular}




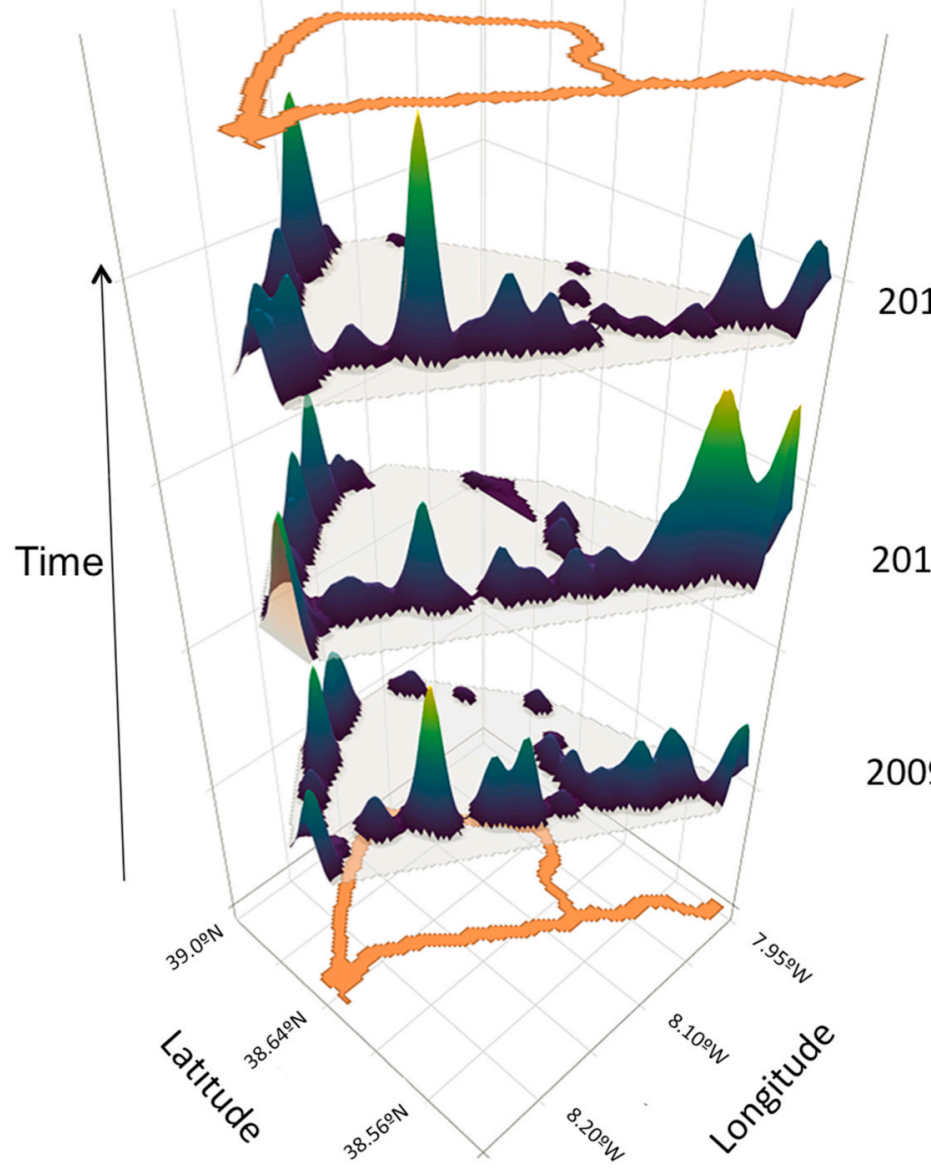

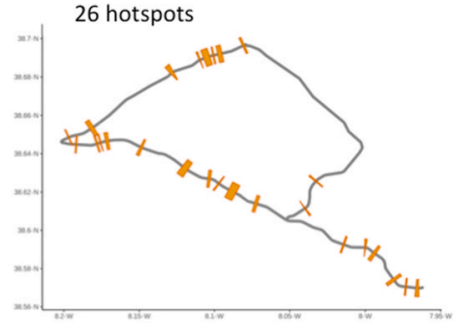

33 hotspots

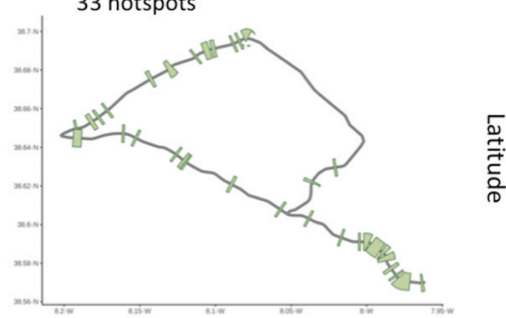

27 hotspots

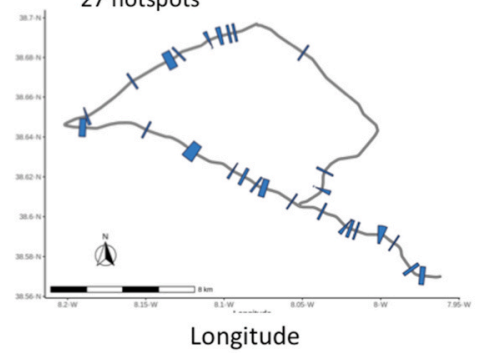

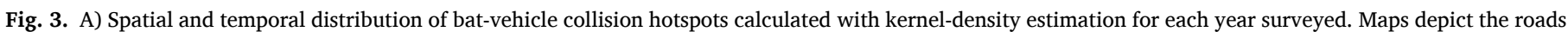

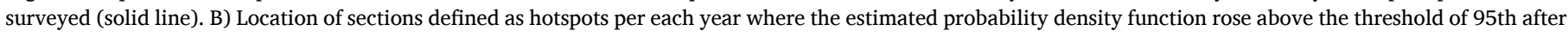
Monte Carlo simulations.

production content between $t$ and $t+1$, was significantly higher in the expansion of hotspot areas $(p=0.038)$ compared with areas where hotspots contracted. Whereas no differences were found when comparing with stable hotspots areas $(p=0.234)$ (Fig. 6). Additionally, hotspots tended to contract in areas where water stress increases ( $\triangle$ WETNESS), comparing with hotspots expansion areas and stable hotspots areas ( $p=0.035 ; p=0.058$, respectively). No significant changes in $\triangle$ NDWI, $\triangle$ TEMPERATURE or $\triangle$ ACTIVITY, from $t$ to $t+1$, were detected among HLC categories (stability vs. expansion vs. contraction) (Fig. 6).

\section{Discussion}

We found a large number of bat roadkills ( $\sim$ three bats killed $/ \mathrm{km}$ ) year) with a tendency to increase slightly along the three years of the study. Bat roadkill hotspots occupied about $12 \%$ of the whole road length, encompassing $61 \%$ of all roadkilled bats. However, the hotspots that remained stable along the three years of study comprised only $3 \%$ of road length, but represented $27 \%$ of roadkills. Our results suggest that bats are consistently more prone to be hit by a car at some specific locations across time. Thus, from the practical perspective, these results has important consequences, because in absence of significant landscape changes, it allows concentrating conservation efforts in spatially restricted areas, greatly improving the efficiency and cost-effectiveness of mitigation actions (Rytwinski et al., 2015). However, measures to reduce bat roadkills, such as overpasses, underpasses, barriers or strips to guide road crossings, are still a matter of debate, and further data are needed to assess their efficiency (Solowczuk, 2019; Claireau et al., 2018, 2019; Berthinussen and Altringham, 2012). Claireau et al. (2019) highlighted that bat overpasses should be located on intersections between roads and bat commuting routes. However, identifying these intersections remains a challenge. Other tools based on the assessment of bat flight trajectories such as acoustic flight path reconstruction (Claireau et al., 2018), may be used to evaluate the bat roadkill risk. Nevertheless, analyses of hotspot stability and strength over time, like we applied in this study, may be a cheaper and easily implemented tool to help to find hazardous locations and decide on efficient placement of mitigation measures. Although an even longer period of sampling might increase the robustness of the study, our analysis represents an advance over other studies concerning roadkill risk locations, and one of the first that examine roadkill risk dynamics across time.

Zimmerman et al. (2017) argue that, for older roads, the rate between road mortality and population abundance in road surroundings should be the preferable, comparing with hotspot location, for informing mitigation priorities, due to the effects of past road mortality (Eberhardt et al., 2013) on long-term population abundance. These authors suggest that over time, the number of bat roadkills on high-traffic stretches with a high road mortality risk declines to the point that there are more roadkills on low-traffic stretches (Zimmerman et al., 2017). In these circumstances, the low-traffic locations may be erroneously identified as priority sections to mitigate, because "false" roadkill hotspots only reflect the previous population depression near high-traffic stretches (Fahrig et al., 1995; Edehardt et al., 2013). Although our study considered a relatively short period of time (three years) and an area where all roads are over 50 years old, our results do not support the Zimmerman and co-authors (2017) hypothesis. Indeed, we did not find a relationship between roadkill hotspot strength and traffic intensity, despite most roadkills having been detected on roads with higher traffic, 


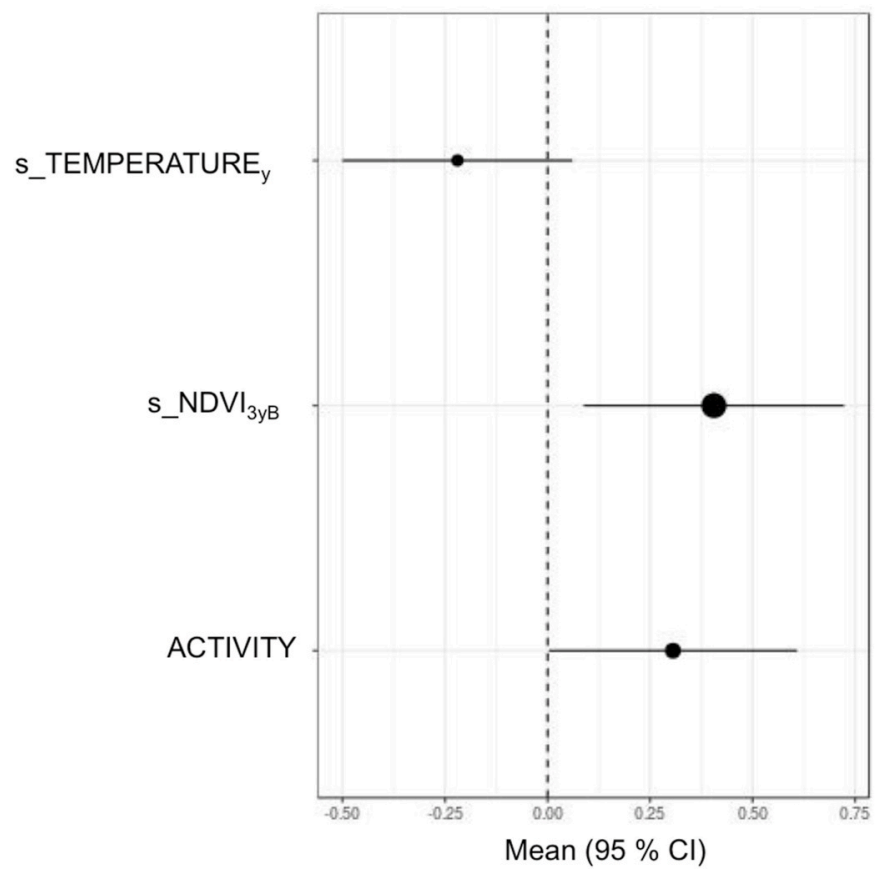

Fig. 4. Coefficient estimates (i.e., median values and $95 \%$ credible intervals (bars) of the posterior distribution of the parameters from the best spatiotemporal models with $\Delta$ AICc $<2$. Credible intervals overlapping 0 (dotted line) indicate that the corresponding effect is not significant at the $5 \%$ level. The dot size relates to the relative importance for each predictor on model selection approach.

\section{Table 2}

Candidate models that were tested to access the potential influence of environmental indices, traffic volume and bat activity on the roadkill risk of the overall community of bats. Parameters: $\mathrm{s}_{-} \mathrm{NDVI}_{3 \mathrm{yB}}-\mathrm{sum}$ of vegetation productivity of 3 years before the reference year when the hotspot was identified. ACTIVITY - bat activity level on the year when hotspot was identified. s_TEMPERATURE $_{\mathrm{y}}$ - daytime land surface temperature. For each model, we present the number of degrees of freedom (df), the Akaike Information Criterion corrected for small samples (AICc), AICc differences $(\triangle \mathrm{AICc})$ and Akaike weights $\left(w_{i}\right)$. The models are ranked by $\triangle \mathrm{AICc}$.

\begin{tabular}{lllll}
\hline Model & df & AICc & AAICc & $w_{i}$ \\
\hline s_NDVI $_{\text {3ув }}+$ ACTIVITY & 6 & 106.75 & 0.00 & 0.35 \\
s_NDVI $_{\text {yув }}$ & 5 & 106.78 & 0.03 & 0.34 \\
s_NDVI $_{\text {3yв }}+$ s_TEMPERATURE & 6 & 108.25 & 1.50 & 0.16 \\
s_NDVI $_{\text {3yв }}+$ ACTIVITY + s_TEMPERATURE & 7 & 108.55 & 1.80 & 0.14 \\
\hline
\end{tabular}

every year.

Our results show that bat roadkill patterns are not random, although hotspot locations may shift along consecutive years. Changes in roadkill hazardousness and hotspot persistence are related to the spatiotemporal dynamics of net primary productivity (NDVI), which is a surrogate of foraging habitat suitability for bats, such as woodland areas and riparian vegetation (Fonderflick et al., 2015; Rainho et al., 2011). Thus, our results agree with previous studies which show that higher habitat quality is a key factor explaining bat roadkill patterns (Medinas et al., 2013; Lesińki, 2007, 2010; Gaisler et al., 2009; Fensome and Mathews, 2016). Similarly, Ascensão and co-authors (2019) showed that roadkill risk and spatiotemporal pattern of road mortality for seven medium-large mammal species in Brazil are highly related to NDVI. A positive relationship between the cumulative NDVI for long periods - three years in our case - seems to be the strongest driver influencing roadkill hotspot strength over time. This is probably because higher values of accumulated aboveground net primary productivity (as measured by NDVI) tend to be associated with high insect availability areas that are temporally stable (Bailey et al., 2004), consistently improving the quality of foraging areas for many close-space aerial insectivorous bats, such as Rhinolophus spp.. High vegetation productivity is also often related to higher tree cover, which provides shelter resources for common bat species as P. kuhlii or P. pipistrellus (Kunz and Lumsden, 2003; Rodríguez-Aguilar et al., 2017). Moreover, in a landscape context with few hedgerows, roadside verges often represent the last remains of dense vegetation strips providing corridors and enhanced foraging opportunities in the immediate roadside vicinity (Abbott et al., 2012; Hale et al., 2015; Laforge et al., 2019), which increases the roadkill risk. Indeed, we also confirmed a strong positive relationship between areas of high bat activity and roadkill risk. Thus, acoustic bat activity monitoring, which is easily measured, may be a simple useful tool to assess roadkill risk (Medinas et al., 2013). We found that mortality risk tends to increase in road sections crossing areas with a slightly lower temperature. Forest areas, riparian galleries, and proximity to water bodies are the main land uses surrounding bat roadkill locations (Medinas et al., 2013). In those areas, due to the vegetation cover and/or proximity to water, the temperature tends to be lower which may explain this tendency.

The increase of vegetation productivity between consecutive years was the most important variable influencing the appearance of new roadkill hotspot locations. Conversely, the increase of water stress, reflecting lower surface moisture, was related to the contraction of hotspots in consecutive years. Our results show that even small temporal changes in habitat suitability, related with changes in moisture and vegetation productivity, influence roadkill patterns, probably due to alterations they induce in bat activity patterns. The changes in these remote-sensing descriptors should reflect mostly changes in local management actions (e.g. changes in grazing intensity, irrigation, crop harvesting, deforestation, etc.), thus linking these management actions with bat roadkill risk. Monitoring local management changes based on field work is logistically unfeasible for large areas or long periods. However, according to our results, moderately detailed freely available remote sensing imagery may adequately describe local environmental disturbance and can be used to evaluate spatiotemporal variation in bat roadkill risk. Evaluation of spatiotemporal habitat suitability changes based on remote-sensing data has already been done for other wildlife groups of different sizes and with different ecological requirements (e.g.. beetles - Lassau and Hochuli, 2008; ungulates - Schweiger et al., 2015). However, to our knowledge, our study is among the pioneers in using these data to identify spatiotemporal changes in road sections with a higher roadkill risk.

Identifying spatially significant roadkill clusters for multiple years is a valuable tool, since it allows the identification and ranking of locations where efforts to reduce wildlife mortality should be focused. On the other hand, concentrating mitigation efforts only on overall bat roadkill hotspots may have limited benefit for some species (Clevenger and Waltho, 2000). Thus, analysing roadkill at the species level or at least at habitat guild level is important, because different spatial or temporal roadkill patterns may be found, depending on specific ecological requirements (Santos et al., 2015). However, this will require a large volume of roadkill data for single species, which is not possible to do in an efficient way for our dataset.

\section{Conclusions}

Overall, our findings confirmed previous results showing that bats are especially susceptible to roadkill in the vicinity of high quality habitats (Medinas et al., 2013; Berthinussen et al., 2012). We were able to demonstrate that bat roadkill hotspot locations may shift along time, accompanying spatiotemporal changes in habitat suitability, and that these can be inferred using freely available remote-sensing imagery, such as NDVI. Furthermore, using multiple year data and complex modelling, such as spatiotemporal analysis, allowed us to classify hotspots according to their strength and persistence, and thus to more precisely target and rank road stretches of interest to install temporal or 


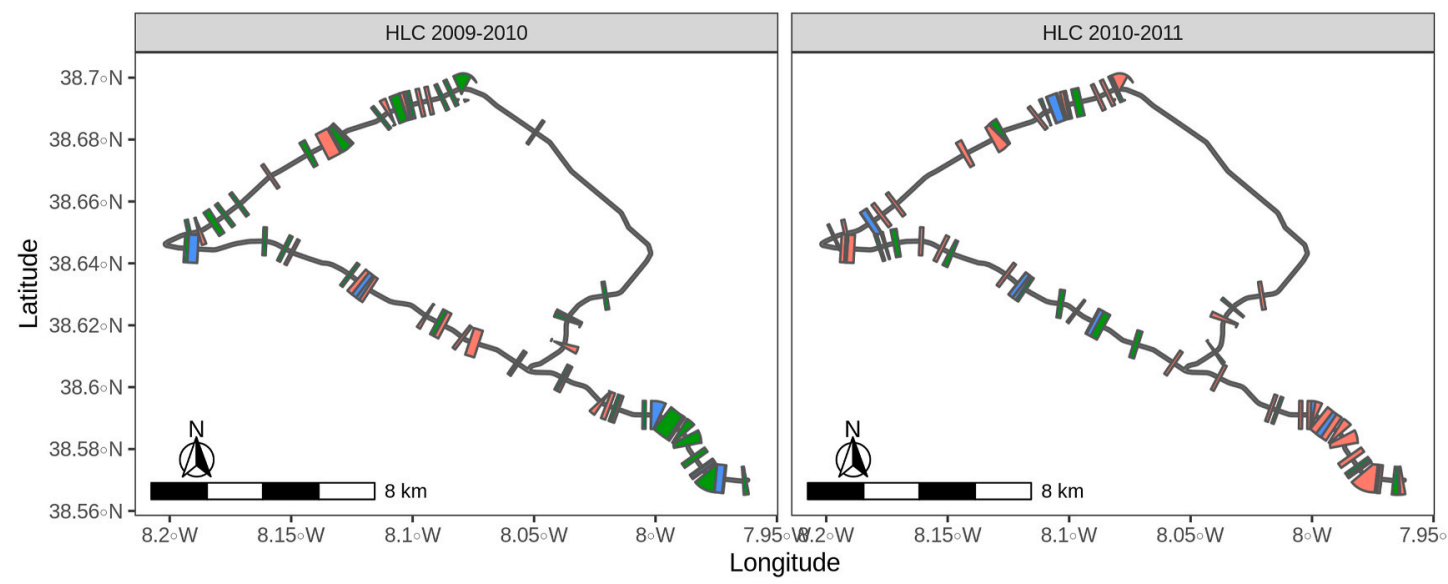

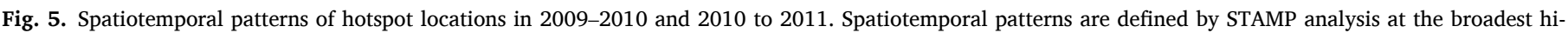

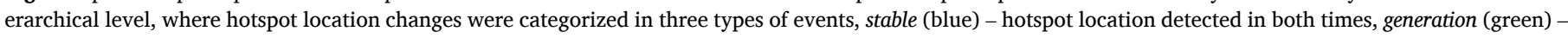

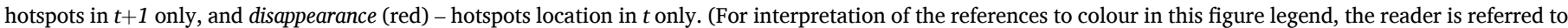
the Web version of this article.)

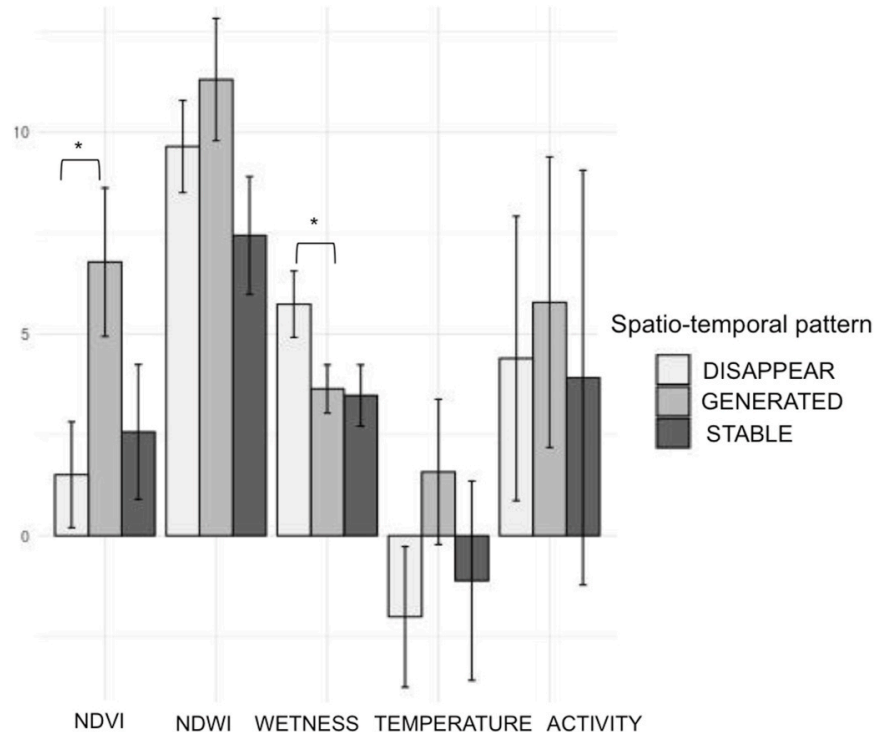

Fig. 6. Mean variation of predictors on hotspot change zone (stability, contraction, or expansion) over 1-year period. An asterisk indicates significant differences between zones of hotspots changes based on $\mathrm{p}<0.05$ using one-way ANOVA and Tukey's post hoc tests.

permanent mitigation measures. Our results support the need of monitoring roadkills across several years to more efficiently mitigate bat casualties. Ideally, monitoring roadkills should be accompanied by monitoring bat populations on road surrounding landscapes, paying particular attention to rare and threatened species that are commonly hit by vehicles (e.g. Rhinolophus spp.)

\section{Credit author statement}

Denis Medinas: developed the ideas, collected the field data and analyse the data, wrote the manuscript. João Tiago Marques: collected the field data and wrote the paper; Pedro Costa: collected the field data; Sara Santos: wrote and revised the manuscript; Hugo Rebelo: revised the manuscript; A. Márcia Barbosa: wrote and revised the manuscript; António Mira: developed the ideas; collected the field data; revised and edited manuscript at all stages.

\section{Declaration of competing interest}

The authors declare that they have no known competing financial interests or personal relationships that could have appeared to influence the work reported in this paper.

\section{Acknowledgements}

We are indebted to all who kindly provided assistance during collection of mortality data, namely: Clara Ferreira, André Lourenço, Filipe Carvalho, Helena Marques, Ana Galatinho. Irene Petrosillo and two anonymous referees provided comments which greatly improved the final version of the manuscript. DM was financed by Fundação para a Ciência e Tecnologia (FCT) with doctoral grant SFRH/BD/104861/ 2014. AMB and HR were supported by FCT and FEDER/COMPETE 2020 through an "Investigador FCT" contract (IF/00266/2013 and IF/04313/ 2017, respectively). This research was supported by the European Regional Development Fund through the COMPETE and National Funds through the FCT and European Commission, under the projects POPCONNECT-PTDC/AAG-MAA/0372/2014 and LIFE LINES-LIFE14-NATPT-001081, respectively.

\section{Appendix A. Supplementary data}

Supplementary data to this article can be found online at https://doi. org/10.1016/j.jenvman.2020.111412.

\section{Reeferences}

Abbott, I., Harrison, S., Butler, F., 2012. Clutter-adaptation of bat species predicts their use of under-motorway passageways of contrasting sizes - a natural experiment. J. Zool. 287, 124-132. https://doi.org/10.1111/j.1469-7998.2011.00894.x.

Altringham, J., Kerth, G., 2016. Bats and roads. In: Voigt, C., Kingston, T. (Eds.), Bats in the Anthropocene: Conservation of Bats in a Changing World. Springer International Publishing AG, Cham, Switzerland, pp. 35-62.

Ascensão, F., Yogui, D., Alves, M., Medici, E., Desbiez, A., 2019. Predicting spatiotemporal pattrens of road mortality for medium-large mammals. J. Env. Manag. 248 https://doi.org/10.1016/j.jenvman.2019.109320.

Bailey, S.A., Horner-Devine, M.C., Luck, G., Moore, L.A., Carney, K.M., Anderson, S., Fleishman, E., 2004. Primary productivity and species richness: relationships among functional guilds, residency groups and vagility classes at multiple spatial scales. Ecography 27, 207-217. https://doi.org/10.1111/j.0906-7590.2004.03631.x.

Barton, K., 2013. MuMIn: multi-model inference. R Package Version 1.9.13. http ://CRAN.R-project.org/package=MuMIn.

Benítez-López, A., Alkemade, R., Verweij, P., 2010. The impacts of roads and other infrastructure on mammal and bird populations: a meta-analysis. Biol. Conserv. 143, 1307-131. http://doi:10.1016/j.biocon.2010.02.009.

Berthinussen, A., Altringham, J., 2012. Do bat gantries and underpasses help bats cross roads safely? PloS One 7, e38775. https://doi.org/10.1371/journal.pone.0038775. 
Bíl, M., Andrášik, R., Janoška, Z., 2013. Identification of hazardous road locations of traffic accidents by means of Kernel density estimation and cluster significance evaluation. Accid. Anal. Prev. 55, 265-273. https://doi.org/10.1016/j. aap. 2013.03.003.

Bíl, M., Andrášik, R., Sedoník, J., 2019. A detailed spatiotemporal analysis of traffic crash hotspots. J. App. Geog. 107, 82-90. https://doi.org/10.1016/j.apgeog.2019.04.008.

Blum, M., Lensky, I., Rempoulakis, P., Nestel, D., 2015. Modelling insect population fluctuations with satellite land surface temperature. Ecol. Model. 311, 39-47. https://doi.org/10.1016/j.ecolmodel.2015.05.005.

Börger, L., Franconi, N., De Michele, G., Gantz, A., Meschi, F., Manica, A., 2006. Effects of sampling regime on the mean and variance of home range size estimates. J. Anim. Ecol. 75, 1393-1405.

Burnham, K.P., Anderson, D.R., 2002. Model Selection and Multimodel Inference: A Practical Information-Theoretic Approach, second ed. Springer-Verlag, New York.

Capo, G., Chaut, J., Arthur, L., 2006. Quatre ans d'étude de mortalité des Chiroptères sur deux kilomèters routiers proches d'un site d'hibernation. Symbioses 15, 45-46.

Chander, G., Markham, B., Helde, D., 2009. Summary of current radiometric calibration coefficients for Landsat MSS, TM, ETM, and EO-1 ALI sensors. Remote Sens. Environ. 13, 893-903.

Choquene, G.L., 2006. Mortalité de chauves-souris suite à des collisions avec des véhicules routiers en Bretagne. Symbioses 15, 43-44.

Claireau, F., Bas, Y., Puechmaille, S.J., Julien, J.-F., Allegrini, B., Kerbiriou, C., 2018. Bat overpasses: an insufficient solution to restore habitat connectivity across roads. J. Appl. Ecol. 56, 573-584. https://doi.org/10.1111/1365-2664.13288.

Claireau, F., Bas, Y., Julien, J.-F., Machon, N., Allegrini, B., Puechmaille, S.J., Kerbiriou, C., 2019. Bat overpasses as an alternative solution to restore habitat connectivity in the context of road requalification. Ecol. Eng. 131, 34-38. https:// doi.org/10.1016/j.ecoleng.2019.02.011.

Clevenger, A.P., Waltho, N., 2000. Factors influencing the effectiveness of wildlife underpasses in banff national park, alberta, Canada. Conserv. Biol. 14, 47-56. http://www.jstor.org/stable/2641903.

Davies, T., Marshall, J., Hazelton, M., 2017. Tutorial on Kernel Estimation of Continuous Spatial and Spatiotemporal Relative Risk with Accompanying Instruction in R, pp. 1-30. R package version 2.2-13.

Dietz, C., von Helversen, O., 2004. Illustrated identification key to the bats of Europe. www.unituebingen.de/tierphys/Kontakt/mitarbeiterseiten/dietz.htm. (Accessed 30 October 2011).

Dietz, C., von Helversen, O., Nil, D., 2009. Bats of Britain, Europe and Northwest Africa, first ed. A \& C Black Publishers Ltd., London.

Dixon, M.D., 2012. Relationship between land cover and insectivorous bat activity in an urban landscape. Urban Ecosyst. 15, 683-695. https://doi.org/10.1007/s11252011-0219-y.

Dormann, C.F., Elith, J., Bacher, S., Buchmann, C., Carl, G., Carré, G., Marquéz, J.R.G., Gruber, B., Lafourcade, B., Leitão, P.J., Munkemuller, T., McClean, C., Osborne, P.E. Reineking, B., Schroder, B., Skidmore, A.K., Zurell, D., Lautenbach, S., 2013. Collinearity: a review of methods to deal with it and a simulation study evaluating their performance. Ecography 36, 27-46. https://doi.org/10.1111/j.16000587.2012.07348.x, 00

Eberhardt, E., Mitchell, S., Fahrig, L., 2013. Road kill hotspots do not effectively indicate mitigation locations when past road kill has depressed populations. J. Wildl. Manag. 77, 1353-1359. https://doi.org/10.1002/jwmg.592.

EP, 2005. Recenseamento Do Tráfego. Estradas de Portugal, E.P.E, Évora.

Evans, J., 2018. Package 'spatialEco', pp. 1-4. R package version 0.0.

Fahrig, L., Rytwinski, T., 2009. Effects of roads on animal abundance: an empirical review and synthesis. Ecol. Soc. 14, 1-20. http://www.ecologyandsociety.or $\mathrm{g} /$ vol14/iss1/art21/.

Fahrig, L., Pedlar, J.H., Pope, S.E., Taylor, P.D., Wegner, J.F., 1995. Effect of road traffic on amphibian density. Biol. Conserv. 73, 177-182. https://doi.org/10.1016/00063207(94)00102-V.

Favilli, F., Bíl, M., Sedoník, J., Andrášik, R., Kasal, P., Agreiter, A., Streifeneder, T., 2018. Application of $\mathrm{KDE}+$ software to identify collective risk hotspots of ungulate-vehicle collisions in South Tyrol, Northern Italy. Eur. J. Wildl. Res. 64 https://doi.org/ 10.1007/s10344-018-1214-x, 64-59.

Fensome, A.G., Mathews, F., 2016. Roads and bats: a meta-analysis and review of the evidence on vehicle collisions and barrier effects. Mamm Rev. 46, 311-323. https:// doi.org/10.1111/mam.12072.

Fonderflick, J., Azam, C., Brochier, C., Cosson, E., Quékenborn, D., 2015. Testing the relevance of using spatial modeling to predict foraging habitat suitability around bat maternity. A case study in Mediterranean landscape. Biol. Conserv. 192, 120-129. https://doi.org/10.1016/j.biocon.2015.09.012.

Freedman, R., Roy, S.S., 2012. Spatial patterning of Manta birostris in United States east coast offshore habitat. Appl. Geogr. 32, 652-659. https://doi.org/10.1016/j. apgeog.2011.07.015.

Gaisler, J., Øehák, Z., Bartonièka, T., 2009. Bat casualties by road traffic (Brno- Vienna). Acta Theriol. 54, 147-155.

Hale, J., Fairbrass, A., Matthews, T., Davies, G., Sadler, J., 2015. The ecological impact of city lighting scenarios: exploring the gap crossing thresholds for urban bats. Global Change Biol. 21, 2467-2478.

Iković, V., Đurović, M., Presetnik, P., 2014. First data on bat traffic casualties in Montenegro. Vespertilio 17, 89-94.

Jepsen, J., Hagen, S., Hogda, K., Ims, R., Karlsen, S., Tommervik, H., 2009. Monitoring the spatio-temporal dynamics of of geometrid moth outbreaks in birch forest using MODIS- NDVI data. Remote Sens. Environ. 113, 1939-1947.

Kelt, D., Van Vuren, D., 1999. Energetic constraints and the relationship between body size and home range area in mammals. Ecology 80, 337-340.
Kociolek, A.V., Clevenger, A.P., St Clair, C.C., Proppe, D.S., 2011. Effects of road networks on bird populations. Conserv. Biol. 25, 241-249. http://10.1111/j.1523-1 739.2010.01635.x.

Kunz, T.H., Lumsden, L.F., 2003. Ecology of cavity and foliage roosting bats. In: Kunz, T., Fenton, M.B. (Eds.), Bat Ecology. University of Chicago Press, Chicago, pp. 3-89.

Laforge, A., Archaux, F., Bas, Y., Gouix, N., Calatayuf, F., Latge, T., Barbaro, L., 2019. Landscape contexto matters for attractiveness and effective use of road underpasses by bats. Biol. Conserv. 237, 409-422. https://doi.org/10.1016/j. biocon. 2019.07.023.

Lassau, S.A., Hochuli, D.F., 2008. Testing predictions of beetle community patterns derived empirically using remote sensing. Divers. Distrib. 14, 138-147. https://doi. org/10.1111/j.1472-4642.2007.00438.x.

Lesiński, G., 2007. Bat road casualties and factors determining their number. Mammalia $71,138-142$.

Lesiński, G., 2008. Linear landscape elements and bat casualties on roads — an example. Ann. Zool. Fenn. 45, 277-280.

Lesiński, G., 2010. Bat casualties on a road crossing a mosaic landscape. Eur. J. Wildl. Res. https://doi.org/10.1007/s10344-010-0414-9.

Long, J., 2018. Package 'stampr': Spatial Temporal Analysis of Moving Polygons in R. R Package version 0.2 .

Loss, S.R., Will, T., Marra, P.P., 2015. Direct mortality of birds from anthropogenic causes. Annu. Rev. Ecol. Evol. Syst. 46, 99-120. https://doi.org/10.1146/annurevecolsys-112414-054133.

Malo, J., Suárez, F., Díez, A., 2004. Can we mitigate animal-vehicle accidents using predictive models? J. Appl. Ecol. 41, 701-710.

Medinas, D., Marques, J.T., Mira, A., 2013. Assessing road effects on bats: the role of landscape, road features, and bat activity on road-kills. Ecol. Res. 28, 227-237. https://doi.org/10.1007/s11284-012-1009-6.

Medinas, D., Ribeiro, V., Marques, J.T., Silva, B., Barbosa, A.M., Rebelo, H., Mira, A., 2019. Road effects on bat activity depend on surrounding habitat type. Sci. Total Environ. https://doi.org/10.1016/j.scitotenv.2019.01.032.

Nelson, T., Krejcar, O., 2011. Quantifying wildlife home range changes. In: Modern Telemetry. InTech Open Access Publisher, Rijeka, Croatia, pp. 269-281.

Okabe, A., Satoh, T., Sugihara, K., 2009. A kernel density estimation method for networks, its computational method and a GIS-based tool. Int. J. Geogr. Inf. Syst. 23 https://doi.org/10.1080/13658810802475491, 7-32.

Oksanen, J., Blanchet, F.G., Kindt, R., Legendre, P., Minchin, P.R., O'Hara, R.B., Simpson, G.L., Solymos, P., Stevens, M.H.H., Wagner, H., 2012. Vegan: Community Ecology Package. R package version 2.5-5.

Palmeirim, J., 1990. Bats of Portugal: Zoogeography and Systematics, vol. 82. University of Kansas Museum of Natural History Miscellaneous Publications, pp. 1-53.

Pinheiro, J.C., Bates, D.M., DebRoy, S., Sarkar, D., 2007. NLME: Linear and Nonlinear Mixed Effects Models. R package version 3.1-83.

R Development Core Team, 2018. R: A Language and Environment for Statistical Computing. R Foundation for Statistical Computing, Vienna.

Rainho, A., 2007. Summer foraging habitats of bats in a Mediterranean region of the Iberian Peninsula. Acta Chiropterol. 9, 171-181. https://doi.org/10.3161/17335329(2007)9[171:SFHOBI]2.0.CO;2.

Rainho, A., Palmeirim, J.M., 2011. The importance of distance to resources in the spatial modelling of bat foraging habitat. PloS One 6, 10. https://doi.org/10.1371/journal. pone.0019227.

Robertson, C., Nelson, T.A., Boots, B., Wulder, M.A., 2007. STAMP: spatial-temporal analysis of moving polygons. J. Geogr. Syst. 9, 207-277 htpp://doi.org/10.101007/ s10109-007-0044-2.

Rodríguez-Aguilar, G., Orozco-Lugo, C., Vleut, I., Vazquez, L.-.B., 2017. Influence of urbanization on the occurrence and activity of aerial insectivorous bats. Urban Ecosyst. 20, 477-488. https://doi.org/10.1007/s11252-016-0608-3.

Rullan-Silva, C., Olthoff, A., Delgado de la Mata, J., Pajares-Alonso, J., 2013. Remote monitoring of forest insect defoliation. A review. Forest Syst. 22, 377-391.

Rytwinski, T., van der Ree, R., Cunnington, G.M., Fahrig, L., Findlay, C.S., Houlahan, J., Jaeger, J., Soanes, K., van der Grift, E.A., 2015. Experimental study designs to improve the evaluation of road mitigation measures for wildlife. J. Environ. Manag. 154, 48-64. https://doi.org/10.1016/j.jenvman.2015.01.048.

Santos, S.M., Carvalho, F., Mira, A., 2011. How long do the dead survive on the road? Carcass persistence probability and implications for road-kill monitoring surveys. PloS One 6, e25383. https://doi.org/10.1371/journal.pone.0025383.

Santos, S.M., Marques, J.T., Lourenço, A., Medinas, D., Barbosa, A.M., Beja, P., Mira, A., 2015. Sampling effects on the identification of roadkill hotspots: implications for survey design. J. Environ. Manag. 162, 87-95. https://doi.org/10.1016/j. jenvman.2015.07.037.

Schofield, H., Mitchell-Jones, A., 2011. The Bats of Britain and Ireland, fourth ed. Vincent Wildlife Trust, Ledbury, UK.

Schorcht, W., Bontadina, F., Schaub, M., 2009. Variation of adult survival drives population dynamics in a migrating forest bat. J. Anim. Ecol. 78, 1182-1190. https://doi.org/10.1111/j.1365-2656.2009.01577.x.

Schweiger, A.K., Risch, A.C., Damm, A., Kneubuhler, R., Haller, M.E., Schaepman, Schutz, M., 2015. Using imaging spectroscopy to predict above-ground plant biomass in alpine GrasslandsGrazed by large ungulates. J. Veg. Sci. 26, 175-190. https://doi.org/10.1111/jvs.12214. M.

Secco, H., Gomes, L., Lemos, H., Mayer, F., Machado, T., Guerreiro, M., Gregorin, R., 2017. Road and landscape features that affect bat roadkills in southeastern Brazil. Oecolog. Aust. 21, 323-336.

Seiler, A., Helldin, J., 2006. Mortality in Wildlife Due to Transportation. The Ecology of Transportation: Managing Mobility for the Environment. Kluwer, The Netherlands.

Shilling, F., Waetjen, D., 2015. Wildlife-vehicle collision hotspots at US highway extents: scale and data source effects. In: Seiler, A., Helldin, J.-O. (Eds.), Proceedings of IENE 
2014 International Conference on Ecology and Transportation, Malmö, Sweden. Nature Conservation, vol. 11, pp. 41-60.

Skórka, P., Lenda, M., Moron, D., Martyka, R., Tryjanowski, P., Sutherland, W.J., 2015. Biodiversity collision blackspots in Poland: separation causality from stochasticity in roadkills of butterflies. Biol. Conserv. 187, 154-163.

Slater, F.M., 2002. An assessment of wildlife road casualties-the potential discrepancy between numbers counted and numbers killed using conventional census. Web Ecol. 3, 33-42. https://doi.org/10.5194/we-3-33-2002.

Smulders, M., Nelson, T.A., Jelinski, D.E., Nielsen, S.E., Stenhouse, G.B., Laberee, K., 2012. Quantifying spatial-temporal patterns in wildlife ranges using STAMP: a grizzly bear example. Appl. Geogr. 35, 124-131. https://doi.org/10.1016/j. apgeog.2012.06.009.

Sokal, R.R., Rohlf, F.J., 1995. Biometry: the Principles and Practice of Statistics in Biological Research, third ed. W. H. Freeman, New York.

Solowczuk, A., 2019. Determinants of the performance of bat gantries installed to carry bat commuting routes over the S3 expressway in Poland. Symmetry 11. https://doi. org/10.3390/sym11081022.

Spellerberg, I., 1998. Ecological effects of roads and traffic: a literature review. Global Ecol. Biogeogr. 7, 317-333.

Spruce, J., Sader, S., Ryan, R., Smoot, J., Kuper, P., Ross, K., 2011. Assessment of MODIS NDVI time series data products for detecting forest defoliation by gypsy moth outbreaks. Remote Sens. Environ. 115, 427-437.
Switzer, P.V., 1997. Site fidelity in predictable and unpredictable habitats. Evol. Ecol. 7, 533-555.

Trombulak, S.C., Frissel, C.A., 2000. Review of ecological effects of roads on terrestrial and aquatic communities. Conserv. Biol. 14, 18-30. https://doi.org/10.1046/j.15231739.2000.99084.x.

van der Ree, R., Smith, D.J., Grilo, C., 2015. The ecological effects of linear infrastructure and traffic: challenges and opportunities of rapid global growth. In: Smith, D.J., Grilo, C., Van Der Ree, R. (Eds.), Handbook of Road Ecology. Wiley-Blackwell, Chichester, pp. 1-9.

Visintin, C., van der Ree, R., McCarthy, M., 2016. A simple framework for a complex problem? Predicting wildlife-vehicle collisions. Ecol. Evol. 6, 6409-6421. https:// doi.org/10.1002/ece3.2306.

Zhang, Z., Yang, H., Yang, H., Li, Y., Wang, T., 2010. The impact of roadside ditches on juvenile and subadult Bufo melanostictus migration. Ecol. Eng. 36, 1242-1250.

Zimmerman, F.T., Kindel, A., Hartz, S.M., Mitchell, S., Fahrig, L., 2017. When road-kill hotspots do not indicate the best sites for road-kill mitigation. J. Appl. Ecol. https:// doi.org/10.1111/1365-2664.

Zuur, A.F., Ieno, E.N., Walker, N.J., Saveliev, A.A., Smith, G.M., 2009. Mixed Effects Models and Extensions in Ecology with R, first ed. Springer, New York. 